\title{
Knowledge Management Strategies in Public Sector-Case Study
}

\author{
Salwa Alhamoudi \\ Institute of Public Administration, Riyadh, Saudi Arabia
}

\begin{abstract}
Knowledge management (KM) as an emerging discipline is becoming increasingly important to organizations seeking to improve their efficiency and competitive abilities. This research aims to investigate knowledge management strategies (KMS) from different fields of knowledge and to identify what are critical factors for effective KMS in public sector and the challenges it faces for the future. This research is possibly the first attempt to investigate empirically the compatibility in one of the most important Saudi public organizations of KMS. To investigate KMS, the research focuses on KM as practiced in the Institute of Public Administration (IPA). The research focuses on factors that may critically influence the development of KMS in public sector in Saudi Arabia. The main question research is: What are the success factors for effective KMS at IPA? The research design was employed with quantitative data collection methods. Questionnaires were distributed to 238 employees in all IPA organizations. The resulting data is analyzed at descriptive and explanatory levels. The research identified 13 critical factors that must be carefully considered to ensure KMS success. The study divided these critical factors into four groups from different perspectives point views to KMS, namely: KM resources, KM technology, KM learning and innovation, and $\mathrm{KM}$ beneficiaries. By integrating the insights from organizational knowledge, information systems, customer-based knowledge, and organizational learning literatures, this study has demonstrated the need to implement complementary strategies.
\end{abstract}

Keywords: knowledge management (KM), knowledge strategy, information technology, organizational learning, knowledge management beneficiaries

\section{Introduction}

Knowledge has been recognized as the basis of competition and the key for business success (Nonaka \& Takeuchi, 1995). The globalization of business, new legislation, increasingly demanding consumers, and the shift from production-based to a knowledge-based economy are creating a revolution that is forcing organizations to utilize and leverage their knowledge to be able to compete (Civi, 2000; Chong \& Choi, 2005). Knowledge management (KM) has been the subject of many discussions over the past decade. KM initiatives, projects, and systems are just beginning to appear in organisations. There is little research and field data to guide the successful development and implementation of such systems or to guide the expectations of the potential benefits of such systems (Civi, 2000; Cormican \& O'Sullivan, 2003). While organizations recognize

Salwa Alhamoudi, Ph.D., assistant professor, Institute of Public Administration, Riyadh, Saudi Arabia.

Correspondence concerning this article should be addressed to Salwa Alhamoudi, IPA, Riyadh, 11141, Saudi Arabia. E-mail: salwa@ipa.edu.sa. 
that $\mathrm{KM}$ is essential for improving performance, many have difficulties in developing strategies for implementation. At present, organizations are challenged to be more creative and innovative to constantly improve performance, to form new partnerships and alliances, and to undertake new ventures outside traditional organizational boundaries (Liu \& Tsai, 2007). KM that is poorly planned and implemented could lead to poor organization knowledge, which in turn can produce poor management decisions, strategies, and policies (Stewart et al., 2000).

Some scholars argued that shifting the focus of organisational KM efforts from technology to people and processes is important for effectively and beneficially managing knowledge (Davenport \& Prusak, 2000; Wiig, 2002). Others asserted that knowledge is a strategic imperative and, therefore, firms must develop strategies for managing knowledge (Zack, 1999). In this research, KM is considered to be one of the fundamental sources of competitive advantage within the context of knowledge management strategy (KMS). Against this background of an emerging literature in strategic management and continual striving to find a workable means of strategic implementation for $\mathrm{KM}$, managers in a wide variety of industries are rethinking their performance measurement systems (Evans, 2005).

Simultaneously, KMS enables the organization to recognize its most immediate and future knowledge priorities, goals, and objectives, and its critical knowledge domains, so as to work toward building strategic knowledge systems and embedding work systems within them (Alavi, Kayworth, \& Leidner, 2006). In addition, KMS will help organizations become more competitive by using new knowledge to reduce costs, increase speed, and meet customer needs (Civi, 2000). Consequently, KMS allows organizations to increase profits, identify new markets, improve efficiency, improve market share, and be more effective. Nevertheless, little attention is paid to different supporting elements, such as organizational culture, strategy, management commitment, information and knowledge systems, continuous improvement, and organizational learning which may be considered to be critical for the successful implementation of KMS. For these reasons, this research attempts to fill this gap by investigating the feasibility of adopting a KMS and identifying the critical factors of success in Institute of Public Administration (IPA) as a case study.

One of the potentially most important contributions of this study is the exposure of data relating different approaches from different fields in KMS to an area that has not previously been explored and documented in detail by researchers. Not only did this study provide an empirical assessment of the essential elements in KM projects, but also assessed the critical success factors (CSFs) of importance for implementation of KM distilled from a comprehensive review of the concepts and practice of KM. This study is possibly the first attempt to investigate empirically the compatibility in one of the most important Saudi public organizations of key ideas of KM and strategic management. This study aims to investigate KMS and to identify what are critical factors for effective KMS in public sector and the challenges it faces for the future. To achieve the aims set out above, the study's main question is: What are the success factors for effective KMS at IPA? To meet the research's aims, the study contains five sections. The first section highlights the background literature research. The second section considers relevant literature from several fields of knowledge strategies perspectives. The third section presents the research methodology employed in the study, and the fourth section provides a comprehensive discussion on the analysis of the results and findings of the quantitative data. The last section deals with the conclusions based on the findings of the research. 


\section{Background Literature}

In a context where competitive advantages are related to knowledge, it can be affirmed that it is important to make an effort to delineate a comprehensive approach, which conceptualises a renewal and dynamic articulation between practices of managing people strategies and KM initiatives (Meireles, Cardoso, \& Marques, 2008). There is an important distinction between KM and KMS: KM is a set of practices and processes, whereas KMS is the orientation/philosophy or the common thread that guides various activities of KM. The content of KM can change depending on a particular firm's needs and business context but the common underlying theme, which is the KMS, remains the same. Knowledge strategy is, however, different from KMS, as explained by Zack (2002, p. 271): "Knowledge strategy is oriented towards understanding what knowledge is strategic and why knowledge management strategy guides and defines the processes and infrastructure (organisation and technological) for managing knowledge". The notion of knowledge strategy relates to how a firm approaches its knowledge needs, whereas KMS relates to how it approaches KM as an activity, for example, Earl (2001) recommended that firms analyse and manage knowledge gaps with the help of three broad KMS: technocratic, economic, and behavioural. These three strategies are further subdivided into seven different strategies: technocratic (systems, cartographic, and engineering), economic (commercial), and behavioural (organisational, spatial, and strategic). These strategies differ in their focus, aim, and critical success factors (Earl, 2001). In this study, the holistic approach is applied to the definition of KM and points to the same fundamental idea that KM refers to the critical issues of organisational adaptation, survival, and competence in the face of discontinuous environmental change. Essentially, it embodies organisational processes that seek a synergistic combination of data and the information-processing capacity of information technologies, and the creative and innovative capacity of human beings (Nonaka \& Von Krogh, 2009). Nonaka and Von Krogh (2009) pointed out that KM is the strategic application of collective company knowledge and know-how to build profits and market share. Knowledge assets, both ideas or concepts and know-how, are created through the computerised collection, storage, sharing, and linking of the corporate knowledge pool. Advanced technologies make it possible to tap into the corporate mind. Hicks, Dattero, and Galup (2006) stated that $\mathrm{KM}$ is a systemised and integrated managerial strategy, which combines IT with the organisational process. $\mathrm{KM}$ is a managerial activity, which develops transfers, transmits stores, and applies knowledge, as well as providing the members of the organisation with real information to be able to react and make the right decisions, in order to attain the organisation's goals.

This view of KMS enables the organisation to identify its critical knowledge domains, its most immediate and future knowledge priorities, goals, and objectives, and to work toward building critical knowledge systems and embedding work systems within them. It advocates a multidisciplinary approach to understanding and researching the field of KM. In the next section, the KMS will be presented in details.

\section{Knowledge Management Strategies}

The research in organizational learning pointed to the importance of learning processes that create knowledge. Armed with high power computing and communication tools, the information technology discipline viewed KM as a technical activity providing IT which stores information. Moreover, knowledge is dynamic in nature and can be accessed through collaboration and communication with experts who have that knowledge (Cormican \& O'Sullivan, 2003). KMS widely accepts that within the literature on KM, there are two 
fundamental approaches: personalisation and codification (Hicks et al., 2006). These two approaches were originally identified and described as being fundamental by Hansen, Nohria, and Tierney (1999). Personalisation takes the viewpoint that the organisation's knowledge resides mainly in the heads of its people, and the main purpose of KM systems is to help people locate it and communicate it to each other. Codification takes the viewpoint that the most relevant knowledge for the organisation can be codified and stored in computer format, so that it may be widely shared. The following is KMS in details.

\section{KM Resource Strategy}

The KMS and approach should be documented and presented to senior management to ensure buy-in and alignment to organisational goals (Lam \& Chua, 2005). Ferdinand (1999) identified the resources of organisation as stocks of available assets that are owned or controlled by a firm, i.e., know-how, financial and physical resources, and human capital. Organisations have the following motives for managing knowledge: capturing lessons learned, avoiding repeating mistakes, and capturing expertise before it leaves (Davenport, De Long, \& Beers, 1998). In this research, the knowledge resource strategy is considered to emphasise the personal knowledge possessed by the firm and the organisational knowledge possessed by the firm (Gehani, 2002). These two kinds of knowledge were supported by KM human resource and KM capturing resource schools. This strategy will include top management support, the organisation structure, resources captured, and human resources knowledge.

\section{KM Technology Strategy (Internal Process)}

Although it is a common mistake to consider that many KM solutions are only limited to certain information systems, knowledge technology is considered to be one of the central drivers of KM (Davenport \& Prusak, 2000). Vera and Crossan (2003) suggested that KM is mainly concerned with providing managers with information technology solutions and prescriptions about how to proactively manage knowledge in organisations. The literature on KM mainly emphasises IT and underscores the need to proactively manage knowledge but offers very little guidance about how to do it, except for prescribing tools, such as groupware, document management systems, email, and internet (Mehrizi, Tehrani, \& Kazemi, 2008). Not surprisingly, most organisations view KM as equivalent to providing the technology infrastructure (Yahya, 2009). Goldman (2010) stated that it is very important to underline the idea that KM does not manage, create, or integrate knowledge or an organisation's results directly. It only has impact on knowledge processes. This kind of process accomplishes its goals through actors involved in the operating process (Goldman, 2010).

In this research, the KM technology strategy will include the processes for KM transfer, information and communication technology for KM, and organisational culture knowledge transfer.

\section{KM Learning and Innovation Strategy}

It is difficult to manage knowledge with the help of information technology, because knowledge is not only explicit, but is also tacit (Polanyi, 1996). Further, knowledge is not only a resource, but a process of knowing (Goldman, 2010). The literature on organisational learning has emphasised that learning is the process that creates knowledge (Vera \& Crossan, 2003). The belief that learning is a means to create and manage knowledge is central to a $\mathrm{KM}$ learning strategy, which is defined in this research as an emphasis on the learning and innovation which evolve from the experiences and best practices of others and sharing and transferring knowledge quickly and efficiently throughout the organisation. Regarding innovation, it is important to note that nowadays it is not enough for organisations to improve continually. Something must make them different. This is 
what makes radical innovation more than an option; it is a necessity (Goldman, 2010). Thus in this study, the researcher uses the term "learning and innovation knowledge" to indicate the concept of organisational knowledge, learning climate, and self-development opportunity

\section{KM Beneficiaries Strategy (External Knowledge):}

Every organisation exists in an environment that conditions the way the organisation conducts its business (Haggie \& Kingston, 2003). Through access to organisational knowledge, employees make sense of their environment and give it meaning. They find new and better ways to perform, work together, break down barriers, share a vision, fill gaps in knowledge, increase productivity, satisfy customers, and ultimately compete (Civi, 2000). Having identified the organisation's competitive knowledge position, Zack (2002) pointed out the fact that organisations which are more innovative have more knowledge, because they explore external knowledge resources. Binney (2001) stated that KM is derived from external data sources, typically focussing on customer-related information. Thus in this study, the researcher uses the term "beneficiary knowledge" to indicate the concept of external knowledge which emphasis the customer focused knowledge which includes three factors: creating advantages for the customers and suppliers, performance evaluation and continuous improvement, and the external environment and benchmarking.

\section{Research Methodology}

This study used the multiple cases approach, because one case study cannot give sufficient evidence to be able make robust generalisations. Multiple cases provide a general understanding and detailed description of each case and then present the themes within each case followed by thematic analysis across cases (Yin, 2009). This research was on four IPA institutions and each case was treated as a separate case but with scope for comprehensive analysis. A case study strategy based on quantitative technique was used in this research. The questionnaire allowed the "what" questions in this research to be answered. Most questionnaire questions were closed-ended and used a five-point Likert scale, so they were easy to complete and analyse. The sample size decision for the population size $(1,000)$ was made up of 278 candidates from IPA's organisations.

\section{Data Analysis and Dissection of Results}

In this section, the research was carried on to investigate the KMS in IPA in order to answer the main question of the research: What are the success factors for effective KMS at IPA? KMS was studied from four perspectives within IPA and the following sub-questions formulated:

(1) What are the success factors for knowledge resources strategy?

(2) What are the success factors for KM information technology strategy?

(3) What are the success factors for KM learning and innovation strategy?

(4) What are the success factors for KM beneficiary strategy?

\section{KM Resources Strategy}

In this section, the study attempts to answer the question of the research: What are the success factors for knowledge resources strategy? The results of $t$-tests in Table 1 can be sorted in descending order, according to the main factors of the KM resource dimension inside IPA.

The results in Table 1 above are found to be very significantly different from the mid-point $3.0(P<0.05)$. The overall mean of KM resource strategy was 3.6556. This suggests that the current systems of top 
management, organisational structure, and storing and retrieving knowledge are available success factors for the application of KMS in IPA. In contrast, human resource KM is a less successful factor in the application of knowledge management strategies in IPA. The study findings from the literature review questionnaires confirm that the factor of top management support is an important success factor in KM implementation strategies. This result is consistent with previous study findings found in the literature review (Davenport et al., 1998; Egbu, 2004; Wong \& Aspinwall, 2005; Chong, 2006). The results in this study suggest that the factor of top management support and the success of KM project implementation are positively linked.

Table 1

One-sample T-test of Statistical Significance of KM Resources in IPA

\begin{tabular}{lcccc}
\hline \multirow{2}{*}{ Knowledge Management Resources } & \multirow{2}{*}{ Mean } & \multicolumn{2}{c}{ One-sample $t$-test } \\
\cline { 3 - 5 } & & $\begin{array}{l}\text { Standard } \\
\text { deviation }\end{array}$ & $t$-statistic & Sig. (1-tailed) \\
\hline 1-1 Top management support & 3.9916 & 0.6874 & 13.277 & $* 0.000$ \\
1-2 Organisational structure & 3.5441 & 0.9284 & 2.395 & $* 0.009$ \\
1-3 Storing and retrieving knowledge & 4.0336 & 0.7484 & 13.062 & $* 0.000$ \\
1-4 Human resources that supported knowledge resources & 3.3550 & 0.9084 & 12.82 & $* 0.000$ \\
Total & 3.6556 & 0.6542 & 6.029 & $* 0.000$ \\
\hline
\end{tabular}

Note. * Significant at level 0.05 .

In relation to organisational structure, the study findings in this research confirm that having an enabling structure is an important factor in KMS. This result is consistent with previous study findings (Chong, 2006; Oliver \& Kandadi, 2006). The results from the survey show that the employees agreed that this factor was a strong available factor in implementing KM projects. Based on these findings, in IPA the organisational structure is a hierarchy; in hierarchical organisational structures, the employees chiefly communicate with their immediate superiors and with their immediate subordinates. Structuring organisations in this way limits information flow and hinders sharing and transfer of knowledge through all the different levels of the organisation.

Relating to storing and retrieving knowledge, the majority of the study findings in this research confirm that storing and retrieving knowledge is a strong available success factor. This result is consistent with study findings in a few previous studies (Davenport \& Prusak, 2000; Civi, 2000; Nonaka, Toyama, \& Konno, 2000; Madhoushi \& Sadati, 2010). This factor was ranked number one in terms of level of availability for knowledge resource organisational strategy. This result reveals that documents stored in repositories are very important for IPA and that it is thought that knowledge should be stored somewhere where it can be easily retrieved. Capturing knowledge and lessons learned helps the organisation avoid repeating mistakes and helps it capture expertise before it leaves (Davenport et al., 1998).

Finally, the study findings in this research confirm that the KM human resource factor is a success factor in KM project implementation. This result is in agreement with findings in previous studies (Chong, 2006; Yahya, 2009). In contrast, the survey suggested that human resources that support knowledge organisational resources in IPA came in as a less available factor in the application of KM inside IPA. Based on these findings, it can be argued that the results indicate that risk-taking is not encouraged, so that new possibilities seem unlikely to emerge. Empowering employees is required to encourage the creation and application of knowledge within an organisation. Empowerment is a driver of knowledge creation. Empowering people gives them a sense of power 
and authority, thus giving them more room to innovate and explore new possibilities (Wong \& Aspinwall, 2005; Yahya, 2009).

\section{KM Technology Strategy (Internal Process)}

In this section, the study attempts to answer the question of the research: What are the success factors for $\mathrm{KM}$ information technology strategy? The results of $t$-tests in Table 2 can be sorted in descending order, according to the main factors of KM technology success inside IPA.

Table 2

One-sample T-test of Statistical Significance of KM Technology in IPA

\begin{tabular}{lcccc}
\hline \multirow{2}{*}{ Knowledge Management Technology } & Mean & \multicolumn{3}{c}{ One-sample $t$-test } \\
\cline { 3 - 5 } & & $\begin{array}{l}\text { Standard } \\
\text { deviation }\end{array}$ & $t$-statistic & Sig. (1-tailed) \\
\hline 2-1 Processes of knowledge transfer & 4.0406 & 0.6274 & 15.752 & $* 0.000$ \\
2-2 Information and communications technology for KM & 4.2500 & 0.7517 & 17.44 & $* 0.000$ \\
3-2 Organisational culture for knowledge transfer & 3.8158 & 0.7011 & 9.149 & $* 0.000$ \\
Total & 4.0364 & 0.5675 & 17.302 & $* 0.000$ \\
\hline
\end{tabular}

Note. $*$ Significant at level 0.05 .

The results in Table 2 above were found to be very significantly different from the mid-point $3.0(P<0.05)$. The overall mean of KM technology strategy was 4.0364 . This study clearly shows that process knowledge transfer is a success factor in the success of KM project implementation as supported by Davenport et al. (1998) and Wong and Aspinwall (2005). A review of the survey results shows that process knowledge transfer affects the success of the implementation of KM projects with a mean of 4.0406. This result indicates that adopting a KM process significantly influences the successful implementation of KMS. The internal process of KM should be defined and addressed within the organisation as creating, organising, transferring, and applying knowledge (Wong \& Aspinwall, 2005). In relation to information and communication technology for KM, the study findings confirm that building an effective ICT infrastructure is an important factor in supporting KM project implementation. Results from the survey shows the ICT infrastructure is a strong factor with a mean of 4.2500. Based on these findings, it can be argued that building an effective ICT infrastructure significantly affects the successful implementation of KM projects and requires a full and deliberate communication strategy. Regular communications should be delivered throughout the organisation highlighting the importance and benefits of the KM project, sharing milestones, and informing staff about what will happen next. Many KM strategies fail, because the employees cannot see the benefits when they share knowledge (Davenport \& Prusak, 2000). Corresponding to organisational culture regarding knowledge transfer, it appears that this factor is one of the most significant factors for KMS (Wong \& Aspinwall, 2005). The study findings in this research confirm that the culture of KM is an important factor in KM project implementation. This result is consistent with previous study findings (Davenport et al., 1998; Wong \& Aspinwall, 2005). This study clearly reveals that the culture of the transfer of knowledge among employees and the success of KM projects are positively linked. Results from the survey show the mean scores on these statements which suggest that the degree of overall culture transferring knowledge is a strong success factor at 3.8158 in the application of KM at IPA. These results indicate that the quality of relationships among staff could have a positive impact on the exchange of knowledge and experiences among the employees. However, the success of KM initiatives depends more on interpersonal interactions and 
social relationships than on the technology itself (Chong \& Choi, 2005). In effect, a culture of trust and confidence among employees is required to encourage the application and development of knowledge within an organisation. Without a high degree of mutual trust, people will be sceptical about the intentions and behaviours of others and thus they will likely withhold their knowledge (Chong \& Choi, 2005).

\section{KM Learning and Innovation Strategy}

In this section, the study attempts to answer the question of the research: What are the success factors for KM learning and innovation strategy? The results of $t$-tests in Table 3 can be sorted in descending order, according to the main factors of KM learning and innovation in IPA.

Table 3

One-sample T-test of Statistical Significance of KM Learning and Innovation in IPA

\begin{tabular}{|c|c|c|c|c|}
\hline \multirow[b]{2}{*}{ Knowledge Management Learning and Innovation } & \multirow[b]{2}{*}{ Mean } & \multicolumn{3}{|c|}{ One-sample $t$-test } \\
\hline & & $\begin{array}{l}\text { Standard } \\
\text { deviation }\end{array}$ & $t$-statistic & Sig. (1-tailed) \\
\hline 3-1 Organisational learning & 3.5567 & 0.7533 & 3.210 & $* 0.001$ \\
\hline 3-2 Learning climate for $\mathrm{KM}$ & 3.4867 & 0.8825 & 15.500 & $* 0.000$ \\
\hline 3-3 Self-development opportunities & 3.4342 & 0.8903 & 14.450 & $* 0.000$ \\
\hline Total & 3.4988 & 0.7392 & 2.063 & $* 0.020$ \\
\hline
\end{tabular}

Note. * Significant at level 0.05 .

The results in Table 3 above are found to be very significantly different from the mid-point $3.0(P<0.05)$. The overall mean of KM learning and innovation in IPA was 3.4988. The study findings in this research confirm that employee learning and innovation is an important factor in $\mathrm{KM}$ project implementation. This result is consistent with findings in previous studies (Wong \& Aspinwall, 2005; Chong, 2006). The results from the survey show the overall mean of organisational learning 3.556 as an available success factor in the application of KM inside IPA. This result indicates that individuals seem to work together and exchange ideas in a way that will enable them to quickly and easily obtain the information that they need to understand fully. Basically, the skills and competences of knowledge workers need to be continuously developed in order for them to produce valuable contributions to an organisation (Wong \& Aspinwall, 2005). If not, as with other tangible assets, their value will depreciate. Hence, organisations have to provide appropriate professional development and learning activities for their employees through training and education. In relation to climate learning KM, as supported by the work of Chong (2006), this study clearly reveals that organisational climate is a success factor in the success of KM projects. The learning climate in IPA does not seem to be a healthy learning climate with a culture of forgiveness. Anxiety may reduce the level of learning and innovation in IPA because of concern about making mistakes. Hence, making mistakes should be viewed as a process of investing in individuals, because it can be a key source for the creation of a learning organisation (Yang \& Wan, 2004). Relating to self-development, it appears that individuals in IPA find it difficult to take the main responsibility and that the managers do not provide appropriate guidance or opportunities for self-development. An overall mean score of 3.4342 shows this is a less available success factor in the application of KM and offers strong evidence that learning opportunities at IPA do not enable staff to share knowledge across the organisation or to share ideas and experiences.

Based on the findings, it can be argued that KM learning and innovation is an important condition for knowledge transfer to occur among individuals and across a group. This is because knowledge transfer requires 
individuals to come together to interact, exchange ideas, and share knowledge with one to another. Consequently, this will lead to the success of KM projects. The results reflect a clear picture of the learning opportunities in IPA which does not suggest a healthy learning climate, not least because the culture of forgiveness and of learning from mistakes is not widely prevalent. Overall, it should be noted that facilities and resources for self-development in IPA are not accessible to everyone.

\section{KM Beneficiaries Strategy (External Knowledge)}

In this section, the study attempt to answer the question of the research: What are the success factors for KM beneficiary's strategy? The results of $t$-test in Tables 4 can be sorted in descending order, according to the main factors of KM beneficiaries in IPA.

Table 4

One-sample T-test of Statistical Significance of KM Beneficiaries in IPA

\begin{tabular}{lllll}
\hline \multirow{2}{*}{ Knowledge Management Beneficiaries } & \multirow{2}{l}{ Mean } & \multicolumn{2}{l}{ One-sample $t$-test } \\
\cline { 3 - 6 } & & $\begin{array}{l}\text { Standard } \\
\text { deviation }\end{array}$ & $t$-statistic & Sig. (1-tailed) \\
\hline 4-1 Creating advantage for the customers and suppliers & 3.6418 & 0.6842 & 5.452 & $* 0.000$ \\
4-2 Performance evaluation and continues development & 3.8361 & 0.7145 & 9.417 & $* 0.000$ \\
4-3 External environment and benchmarking & 3.7941 & 0.8430 & 7.213 & $* 0.000$ \\
Total & 3.7514 & 0.6446 & 8.410 & $* 0.000$ \\
\hline
\end{tabular}

Note. * Significant at level 0.05 .

The results in Table 4 above are found to be very significantly different from the mid-point $3.0(P<0.05)$. The overall mean of the KM beneficiaries dimension was 3.7514. This study clearly reveals that creating advantage for customers and suppliers is a success factor for the success of KM project implementation as is supported by the work of Pelau, Vladoi, Fuefezan, Binca, and Ghinea (2010). The results from this study suggest that factors relating to KM customers and suppliers are positively linked with success of KM projects. The overall mean of creating advantages for customers and suppliers was 3.6418. This result indicates that focusing on customers and suppliers has become an important consideration and an available success factor in the application of KM inside IPA. Customer-focused knowledge provides knowledge about customer demands in order to justify the internal processes to meet the customer needs; however, it should be taken into consideration that customer needs will undoubtedly change over time. Based on these findings, it can be argued that a complete understanding of existing customers enables IPA to meet current market challenges which represents a new potential market and source of competitive advantage, as well as being a means of retaining existing customers, and improving customer satisfaction.

In relation to performance evaluation and continuous improvement, the study confirms that performance evaluation and continuous improvement is an important factor in KM project implementation. This result is in agreement with findings from previous studies (Feher, 2004). Results from the survey suggested a mean of 3.836. Based on these findings, it can be argued that evaluating performance and outcomes is an important factor in KM project implementation. Further, evaluating them enables organisations to track the progress of KM and to determine its benefits and effectiveness (Yahya, 2009)

In relation to external environment and benchmarking, the results of the study revealed that the factor of benchmarking best practices is one of the important success factors in KM project implementation. This result is 
consistent with findings from previous studies (Cook, Seiford, \& Zhu, 2004). The results this study suggest that the factor of benchmarking and the success of KM projects are positively linked. Results from the survey suggested a similar degree of importance. Based on these findings, it can be argued that benchmarking best practices significantly influences the successful implementation of KM.

\section{Conclusions}

This study provided insights into four KMS, namely: KM resources, KM technology, KM learning and innovation, and $\mathrm{KM}$ beneficiaries. By integrating the insights from organisational knowledge, information systems, customer-based knowledge, and organisational learning literatures, this study has demonstrated the need to implement complementary strategies. These strategies are not independent of each other and each strategy should be used in conjunction with the others.

Based on KM resources strategy findings, it can be argued that it is important to implement KM resources strategy in order to exploit the organisation's existing knowledge. This reflects a clear picture about the KM resource strategy, which suggests that top management support should continuously provide the necessary resources and budget through all KMS stages as an important condition of successful KMS (Wong \& Aspinwall, 2005; Chong, 2006). Further, a flat or network organisational structures which fosters cross-functional communication and where functional barriers are low, appear to facilitate KM more effectively. Moreover, through empowerment, employers can show that they value their employees' expertise and help them communicate their knowledge by creating ways to generate, store, and share knowledge. In IPA, employee involvement came in as a less available factor in supporting the implementation of KM. Employee involvement is critical to achieving effective implementation of projects through a sense of ownership amongst employees. Further, organisations must realise that when employees are involved, they give more commitment during the $\mathrm{KM}$ project implementation and begin to think of the best ways of delivering best results in their jobs. Finally, reward systems do not appear to be structured to assist learning and innovation in IPA. The regulation of IPA is achieved through punishment more than reward, which can be a major block to transferring and sharing knowledge.

With respect to KM technology strategy findings, it can be argued that there should be specific KM processes to acquire knowledge, store and organise it, and to share and disseminate it in a systematic way to enable employees to access and reuse it easily and effectively. In essence, IPA should therefore set up an adequate information and communication system that would assist access and retrieval of information, and support collaboration and communication between IPA's employees. However, the success of KM initiatives depends more on interpersonal interactions and social relationships than on the technology itself (Yang \& Wan, 2004). In effect, a culture of trust and confidence among employees is required to encourage the application and development of knowledge within an organisation. Without a high degree of mutual trust, people will be sceptical about the intentions and behaviours of others, thus they will likely withhold their knowledge (Chong \& Choi, 2005).

Based on KM learning and innovation strategy findings, it can be argued that KM learning and innovation is an important condition for knowledge transfer to occur among individuals and across a group. This is because knowledge transfer requires individuals to come together to interact, exchange ideas, and share knowledge with one to another. Consequently, this will lead to the success of KM projects. The results reflect a clear picture of the learning opportunities in IPA which does not suggest a healthy learning climate, not least because the culture of forgiveness and of learning from mistakes is not widely prevalent. Overall, it should be noted that facilities and 
resources for self-development in IPA are not accessible to everyone.

In relation to external environment and benchmarking, the results of the study revealed that the factor of benchmarking best practices is one of the important success factors in KM project implementation. This result is consistent with findings from previous studies (Cook et al., 2004). Results from the survey suggested a similar degree of importance. Based on these findings, it can be argued that benchmarking best practices significantly influences the successful implementation of KM.

This study has presented a holistic review of KM strategies implementation through a comprehensive scrutiny of the relevant literature, an exploratory survey of IPA's employees for the case studies. It has provided a detailed discussion of critical factors of KM strategies implementation. The study identified 13 critical factors that must be considered carefully to secure strategic KM success.

\section{References}

Alavi, M., Kayworth, T., \& Leidner, D. (2006). An empirical examination of the influence of organisational culture on knowledge management practices. Journal of Management Information Systems, 22(3), 191-191.

Binney, D. (2001). The knowledge management spectrum-understanding the KM landscape. Journal of Knowledge Management, $5(1), 33-42$.

Chong, S. (2006). KM critical success factors: A comparison of perceived importance versus implementation in Malaysian ICT companies. The Learning Organisation, 13(3), 230-256.

Chong, S. C., \& Choi, Y. S. (2005). Critical factors in the successful implementation of knowledge management. Retrieved from $\mathrm{http}: / /$ www.tlainc.com/articl90.htm

Civi, E. (2000). Knowledge management as a competitive asset: A review. Marketing Intelligence \& Planning, 18(4), 166-174.

Cook, W., Seiford, L., \& Zhu, J. (2004). Models for performance benchmarking: Measuring the effect of e-business activities on banking performance. Omega, 32, 313-322.

Cormican, K., \& O’Sullivan, D. (2003). A scorecard for supporting enterprise knowledge management. Journal of Information and Knowledge Management, 2(3), 191-202.

Davenport, T. H., \& Prusak, L. (2000). Working knowledge: How organizations manage what they know. Boston: Harvard Business School Press.

Davenport, T., De Long, D., \& Beers, M. (1998). Successful knowledge management projects. Sloan Management Review, 39(2), 43-57.

Earl, M. (2001). Knowledge management strategies: Toward a taxonomy. Journal of Management Information Systems, 18(1), $215-215$.

Egbu, C. (2004). Managing knowledge and intellectual capital for improved organisation innovations in the construction industry: An examination of critical success factors. Engineering, Construction and Architectural Management, 11(5), 301-315.

Evans, N. (2005). Assessing the balanced scorecard as a management tool for hotels. International Journal of contemporary Hospitality management, 17(5), 376-390.

Feher, P. (2004). Combining knowledge and change management at consultancies. Electronic Journal of Knowledge Management, 2(1), 19-32.

Ferdinand, A. T. (1999). Strategic pathways toward sustainable competitive advantage (DBA thesis, Southern Cross University).

Gehani, R. R. (2002). Chester Barnard's “executive” and the knowledge-based firm. Management Decision, 40(10), 980-991.

Goldman, F. (2010). A structured model of relationship dynamics between organisational knowledge management and organisational learning. Proceedings from the 2nd European Conference on Intellectual Capital, Lisbon, Portugal.

Haggie, K., \& Kingston, J. (2003). Choosing your knowledge management strategy. Retrieved from http://www.tlainc.com/jkmpv4.tm

Hansen, M., Nohria, N., \& Tierney, T. (1999). What's your strategy for managing knowledge? Harvard Business Review, 77(2), 106-116.

Hicks, R. Dattero, R., \& Galup, S. (2006). The five-tier knowledge management hierarchy. Journal of Knowledge Management, 10(1), 19-31. 
Lam, W., \& Chua, A. (2005). The mismanagement of knowledge management. Alsip Proceedings, 57(5), 424-433.

Liu, P. L., \& Tsai, C. H. (2007). The study of R\&D management on new product development performance in Taiwan's HI-tech industries. Retrieved from http://www.scientificjournals.org/journals2007/articles/1053.htm

Madhoushi, M., \& Sadati, A. (2010). Knowledge management, antecedent of organisational innovation and competitiveness. Proceeding from the 2nd European Conference on Intellectual Capital, ECIC, Italy.

Mehrizi, M., Tehrani, H., \& Kazemi, M. (2008). Towards and integrated framework of knowledge management between project and organisation level. Proceedings from the 9th European Conference of Knowledge Management, Southampton Solent University, UK.

Meireles, A., Cardoso, L., \& Marques, J. (2008). Organisation commitment, knowledge management and social economy: An empirical study. Proceedings from the 9th European Conference of Knowledge Management, Southampton Solent University, UK.

Nonaka, I., \& Takeuchi, H. (1995). The knowledge-creating company. New York: Oxford University Press.

Nonaka, I., \& Von Krogh, G. (2009). Tacit knowledge and knowledge conversion: Controversy and advancement in organisational knowledge creation theory organisation science. Organization Science, 20(3), 635-652.

Nonaka, I., Toyama, R., \& Konno, N. (2000). SECI, Ba, and leadership: A unified model of dynamic knowledge creation. Long Range Planning, 33(1), 5-34.

Oliver, S., \& Kandadi, K. (2006). How to develop knowledge culture in organisations? A multiple case study of large distributed organisations. Journal of knowledge Management, 10(4), 6-24.

Pelau, C., Vladoi, A., Fuefezan, M., Binca, V., \& Ghinea, V. (2010). The influence of knowledge dynamics on consumer behaviour. Proceeding from the 2nd European Conference on Intellectual Capital, ECIC, Italy.

Polanyi, M. (1996). The tacit dimension. New York: Doubleday.

Stewart, K., Baskerville, R., Storey, V., Senn, J., Raven, A., \& Long, C. (2000). Confronting the assumptions underlying the management of knowledge: An agenda for understanding and investigating knowledge management. ACM SIGMIS Database, 31(4), 41-53.

Vera, D., \& Crossan, M. (2003). Organisational learning and knowledge management: Toward an integrative framework. In M. Easterby-Smith, \& M. Lyles (Eds.), Handbook of organisational learning and knowledge management. Oxford: Blackwell Publishing.

Wiig, K. (2002). Knowledge management in public administration. Journal of Knowledge Management, 6(3), 224-239.

Wong, K., \& Aspinwall, E. (2005). An empirical study of the important factors for knowledge-management adoption in the SME sector. Journal of Knowledge Management, 9(3), 64-82.

Yahya, K. (2009). Power-influence in decision making, competence, and organizational culture in public organizations. Journal of Public Administration Research and Theory, 19(2), 385- 408.

Yang, J. T., \& Wan, C. S. (2004). Advancing organisational effectiveness and knowledge management implementation. Tourism Management, 25(5), 593-601.

Yin, R. K. (2009). Case study research design and methods (4th ed.). London: SAGE Publications Ltd..

Zack, M. (1999). Developing a knowledge strategy. California Management Review, 41(3), 125-145.

Zack, M. (2002). Epilogue: Developing a knowledge strategy. In N. Bontis, \& C. W. Choo (Eds.), The strategic management of intellectual capital and organisational knowledge (pp. 268-276). Oxford: Oxford University Press. 